\title{
O Ensino Médio regular em foco: análise do Projeto de Desenvolvimento Pedagógico Institucional (PDPI)
}

\author{
Valéria Moreira Rezende*
}

\begin{abstract}
Resumo
Realizada na perspectiva dos estudos sobre a cultura escolar, esta pesquisa focaliza o Ensino Médio no processo de implantação de um programa de qualidade. Objetiva investigar o que se entende por qualidade do Ensino Médio regular na rede pública estadual em Minas Gerais, no processo de implantação do Projeto de Desenvolvimento Pedagógico Institucional - PDPI como parte integrante do Programa Escolas-Referência (PER) pelo governo mineiro. Tomaramse como alvo da pesquisa duas escolas públicas do interior de Minas Gerais que apresentam concepções sobre qualidade do ensino ligadas à forma como receberam e implantaram o projeto. A escola é entendida como instância autoorganizada para a produção de regras formais e informais características das organizações sociais. Sob esse modo de olhar, é vista no âmbito de contradições sociais que ora dificultam, ora impulsionam o projeto educacional. A pesquisa incluiu os seguintes procedimentos: análise documental, entrevistas semi-estruturadas, observação. Percebeu-se que a escola e seus sujeitos defrontaram-se com uma série de ingerências na implantação do Projeto de Desenvolvimento Pedagógico Institucional, que transformam a sonhada escola em pesadelo. Os resultados revelaram que o sonho se desfaz diante de um projeto que se propõe, retoricamente, a resgatar uma "qualidade do ensino" ainda suscetível a indefinições.
\end{abstract}

Palavras-chave: Qualidade, Ensino Médio, Políticas educacionais.

Regular High School education in focus: the analysis of the Institutional Educational Development Project (PDPI)

\begin{abstract}
Set under the perspective of school culture studies, this research focuses on high school education inserted under the process of implementation of a quality program. This article aims at investigating what is conceived as regular high school quality in the extent of state public education of Minas Gerais, on the process of implementation of the Institutional Educational Development Project (Projeto de Desenvolvimento Pedagógico Institucional - PDPI) as part of the Reference Schools Project (Projeto Escolas-Referência-PER) instituted by the government of Minas Gerais. This research has taken as scope two public schools

\footnotetext{
* Professora do curso de Pedagogia na Universidade Federal de Uberlândia, Minas Gerais,
} Brasil.
\end{abstract}




\section{Valéria Moreira Rezende}

from the countryside of the State of Minas Gerais, which have presented conceptions about education quality connected to the way they have received and implemented the project. School is therefore understood as a self-organized instance towards the production of formal and informal rules, which are peculiar to social organizations. Under this point of view, school is seen on the range of social contradictions that sometimes hamper, and other times promote the educational project. The research has included the following proceedings: documentary analysis, interviews, observation. Through the analysis, it was clear that the school and its subjects confronted a series of mismanagements on the implementation of the PDPI, which turned the dreamed school into a nightmare. The results have revealed that the dream is undone before a project that rhetorically proposes itself to redeem "education quality" when that is still undefined.

Keywords: Quality, High School education, Educational Policies.

\section{Introdução}

Inserida no campo das Ciências Sociais, esta investigação coloca-se na perspectiva dos estudos sobre a cultura escolar, tendo em vista a compreensão da educação como fenômeno da cultura e pressupondo um lugar de interrogação interessado nas práticas e saberes escolares.

Esta pesquisa coloca em cena duas escolas públicas estaduais de Ensino Médio - denominadas Escola Casemiro Alvarez e Escola Agostino Miranda, do interior do estado de Minas Gerais -, evidenciando suas características comuns e singularidades, bem como a orientação de suas práticas educativas em relação à qualidade do ensino. Essas unidades escolares estavam inseridas no Projeto Escolas-Referência (PER), desenvolvido pelo governo do estado de Minas Gerais no biênio 2006-2007, por meio da Secretaria da Educação, que tinha como principal objetivo a ampliação e a melhoria do Ensino Fundamental e a universalização e melhoria do Ensino Médio. ${ }^{1}$

Pretendeu-se flagrar nesta investigação em que medida a forma peculiar como cada escola desenvolve sua prática educativa e lida com as interferências externas, bem como de que maneira suas ações interferem na qualidade do ensino oferecido. Buscou-se também compreender as relações entre essas condições e a qualidade do ensino oferecido naquelas duas escolas, especificamente no que se refere à implantação de um Programa que se propõe a promover a qualidade do ensino, por meio de estratégias articuladas com o Plano de Desenvolvimento Pedagógico - PDPI.

Para pensar numa escola como organização, é necessário pensar nas pessoas que a constituem e que trabalham com vistas a alcançar objetivos comuns, assim como nas relações que estabelecem entre si. Uma escola não deixa de ser um conjunto de indivíduos que interagem. O que fizerem de suas 
O Ensino Médio regular em foco: análise do Projeto de Desenvolvimento Pedagógico Institucional (PDPI)

relações vai se constituir na identidade da organização. Em grande parte, tais relações dependem da posição que cada um ocupa no universo hierarquizado da organização. E cada escola tem sua particularidade, como afirma Hutmacher (1995, p. 55): "Não é a escola em geral, mas sim o estabelecimento de ensino com a sua identidade específica, que, na subjetividade dos professores e alunos, constitui o lugar concreto de trabalho e de investimento".

Os estudos de Barroso (1996), Canário (1996), Lima (1991, 1996) e Nóvoa (1995) proporcionam a percepção de que a organização da prática na escola e o cotidiano escolar não são determinados apenas pelas disposições legais e administrativas, concretamente decididas por órgãos exteriores à escola, isto é, pela instância da qual esta depende. A escola é entendida como instância auto-organizada para a produção de regras formais e informais características das organizações sociais. Sob esse modo de olhar, é vista no âmbito de contradições sociais que ora dificultam, ora impulsionam o projeto educacional, como estabelecimento de ensino e aprendizagem, com práticas e saberes, assumindo assim sua função formadora.

Por outro lado, como argumenta Pérez Gómez (2001), a lógica que na atualidade permeia a educação é a lógica do mercado, na perspectiva neoliberal. Por conseguinte, na formação de docentes, a preocupação pela qualidade concentra-se na produtividade, para a qual o produto final, não o processo, é o mais importante. Fazer muitas coisas ao mesmo tempo e obter os melhores resultados por meio dos mais aligeirados processos é a tônica imperiosa da ideologia neoliberal que encontra receptividade nos ambientes educacionais: "O conhecimento na era do livre mercado se vincula diretamente às suas aplicações tecnológicas e adquire valor, porque serve para otimizar a rentabilidade de qualquer processo ou de qualquer produto: maximiza os produtos, reduzindo ao mínimo os custos" (PÉREZ GÓMEZ, 2001, p. 139).

\section{O que está por trás da tão almejada qualidade do ensino}

O conceito de qualidade do ensino é complexo e não deve se limitar à sinalização de determinado nível de rendimento escolar dos alunos - deve incluir também um conjunto de aprendizagens relacionadas ao desenvolvimento pessoal, afetivo social e moral do aluno:

[...] os resultados dos alunos são influenciados por seu nível social que depende em grande medida de suas condições socioculturais e familiares [...]. A qualidade do ensino deve levar em conta as finalidades gerais da educação, o contexto em que se produz e o conjunto de seus processos. (MARCHESI; MARTíN, 2003, p. 21)

No entanto, os autores ressaltam que não apenas as condições socioculturais dos alunos determinam esse processo e apontam índices da 


\title{
Valéria Moreira Rezende
}

baixa ou alta qualidade do ensino. É necessário que o sistema educacional assegure a melhor educação possível para todos os alunos. A partir daí, apresentam um conceito de qualidade do ensino:

\begin{abstract}
Uma escola de qualidade é aquela que estimula o desenvolvimento das capacidades cognitivas, sociais, afetivas e morais dos alunos, contribui para a participação e a satisfação da comunidade educativa, promove o desenvolvimento profissional dos docentes e influi com sua oferta educativa em seu ambiente social. Uma escola de qualidade leva em conta as características de seus alunos e de seu meio social. Um sistema educacional de qualidade favorece o funcionamento desse tipo de escola e apoia particularmente aquelas que escolarizam alunos com necessidades educativas especiais ou que estão situados em zonas socialmente ou culturalmente desfavorecidas. (MARCHESI; MARTíN, 2003, p. 22)
\end{abstract}

A partir de tais considerações, é possível afirmar que são vários os fatores que interferem no fator de qualidade do ensino, daí a complexidade de se elaborar uma definição mais precisa. Também não é correto considerar de qualidade o resultado objetivo de aprendizagem, descontextualizado de suas práticas, valores e sentimentos.

Nessas circunstâncias, não é tarefa simples estabelecer parâmetros de aferição da qualidade da educação por meio da definição dos indicadores de qualidade.

Azanha (1995) resgata esse conceito de qualidade - ou, melhor, de má qualidade-como algo que não foge à realidade vivenciada nas escolas, mas está intrinsecamente ligado ao que acontece no seu interior.

O que interessa é descrever as práticas escolares e os seus correlatos (objetivados em mentalidades, conflitos, discursos, procedimentos, hábitos, atitudes, regulamentações, "resultados escolares", etc.). Somente o acúmulo sistemático dessas descrições permitirá compor um quadro compreensível da situação escolar, ponto de partida para um esforço de explicação e reformulação. Esse quadro permitirá provavelmente que a expressão "má qualidade do ensino", que é nuclear nas descrições das crises da escola, apareça não mais como o "efeito objetivo" e inexorável dessa crise, mas como o correlato de uma mentalidade pedagógica com profundas raízes em determinadas condições sociais. Somente um positivismo tosco nos impede de observar que má "qualidade do ensino" não é uma entidade real, mas linguística. (AZANHA, 1995, p. 72, grifos do autor) 
O discurso genérico da melhoria da qualidade de ensino em decorrência de reformas educativas está constantemente em pauta: nos meios de comunicação de massa, em revistas e jornais, nas entrevistas de autoridades, nos documentos oficiais, etc. Difícil fazer uma abordagem crítica do que representa essa expressão "qualidade do ensino", para poder avaliar os seus efeitos.

Barroso (1997) acredita que o conceito de qualidade camufla um conjunto de perspectivas de práticas divergentes que, muitas vezes, trazem um sentido diferente do que se pretende anunciar. $O$ autor examina a "ilusão racionalista" que esconde um caráter artificial da qualidade sob a capa de uma visão unitária simplista e normativa das políticas que desenvolvem sistemas de qualidade em nome de uma suposta neutralidade técnica dos instrumentos que são usados para controlar as ações envolvidas nessas políticas.

No "discurso" da nova ordem social, para Barreto (2001), nível de excelência, eficiência, eficácia e efetividade seriam ganhos do sistema educacional. Essa estratégia proporciona otimização dos recursos físicos e humanos, potencializando a melhoria do processo de ensino-aprendizagem e a qualidade do serviço educacional.

Na lógica política, a defesa da "qualidade" e o ato de impor normas e regras a serem seguidas para a efetivação de um nível de qualidade assumem uma característica retórica com objetivo específico de encobrir outros elementos. Esta política de modernização, que visa promover a "qualidade" e "excelência" do ensino, tem como finalidade conciliar a eficiência e a equidade no funcionamento do sistema educativo. Nesta lógica, as escolas são convocadas a responder ao investimento que recebem por meio de comprovações de eficiência "externa", para atender as necessidades do mercado, e "interna", na melhora do desempenho de suas atividades.

Outros objetivos são reduzir o monopólio público da educação e introduzir no sistema educativo a lógica de mercado. Ou seja, favorecer a desobrigação do Estado, em termos de responsabilidade e custos, para com a educação, de modo que "a escola passa a ser gerida como uma empresa no quadro de um sistema de concorrência em que a satisfação do consumidor decide a sua rentabilidade e eficácia" (BARROSO, 1997, p. 27).

Para Frigotto e Ciavatta (2003, p. 93), a retórica do discurso neoliberal enfatiza a globalização, o Estado mínimo, a reestruturação produtiva, a sociedade do conhecimento, a qualidade total e a empregabilidade, entre outros aspectos, "[...] cuja função é a de justificar a necessidade de reformas profundas no aparelho do Estado e nas relações capital/trabalho".

Outro objetivo diz respeito à necessidade do Estado de preservar o controle do sistema educativo para que haja o reconhecimento por parte da sociedade, que considera esse sistema um elemento vital. Assim, ao mesmo 


\section{Valéria Moreira Rezende}

tempo em que promove a interferência da lógica de mercado no gerenciamento da educação, o Estado reserva para si o controle e o monitoramento do sistema e impõe sua subordinação: "[...] a política de qualidade acaba por ser uma política de normatização de imposição de modelos que limita a retórica da autonomia e do livre arbítrio tão cara ao discurso neoliberal" (FRIGOTTO; CIAVATTA, 2003, p. 96).

Dessas considerações, infere-se que a avaliação da qualidade do ensino é complexa e só possível quando se consideram diversas variáveis. Além disso, é indispensável meticulosa investigação sobre a escola e o ensino, considerando-se as condições que a escola oferece para a realização do trabalho pedagógico.

\section{A implantação do PDPI nas escolas de "excelência"}

As duas escolas envolvidas na pesquisa oferecem o Ensino Médio regular básico, cujo objetivo principal, como etapa final da Educação Básica, é a formação geral, conforme a proposição legal que subsidia esse nível de ensino no Brasil.

Para atingir seus objetivos, o governo mineiro propôs-se, com a implantação do Projeto Escolas-Referência, a desenvolver ações consideradas essencialmente prioritárias na concretização das mudanças necessárias para a transformação do perfil da escola mineira. Dentre essas ações, estava a elaboração e a implantação do Plano de Desenvolvimento Pedagógico Institucional (PDPI) pelas escolas participantes, as quais se serviriam de uma metodologia específica a ser proposta de modo a atender a exigência da participação de todos.

Sob orientação, acompanhamento e avaliação da instância regional, as escolas Casemiro Alvarez e Agostino Miranda elaboraram seus PDPI, tendo como eixo um conjunto de indicadores de qualidade determinados pela Secretaria da Educação (SEE-MG): gestão escolar; integração escola/comunidade; programação sociocultural; relações interpessoais; organização do espaço escolar; processo ensino-aprendizagem; conteúdos/currículo; organização do tempo escolar; avaliação da aprendizagem; planejamento didático; atendimento diferenciado ao aluno; recursos didáticos. Em outras palavras, as escolas não tiveram opção para elaborar seus próprios indicadores conforme suas especificidades. O enquadramento prévio dos indicadores de qualidade pela SEE-MG resultou na elaboração pelas escolas de projetos sem significativas diferenças; embora as escolas constituíssem realidades diferentes, os levantamentos diagnósticos que apresentaram foram semelhantes.

A orientação emanada da SEE-MG era que as escolas, ao elaborar seus PDPIs, deviam sonhare, no sonho, transpor para o papel o ideal de escola que desejassem ter. Assim, durante os encontros realizados com a equipe técnica da Superintendência Regional de Ensino (SRE), as escolas foram incenti- 
O Ensino Médio regular em foco: análise do Projeto de Desenvolvimento Pedagógico Institucional (PDPI)

vadas, no seu coletivo, a materializar seus sonhos em forma de projeto de uma escola de qualidade, conforme anuncia a diretora da Escola Casemiro Alvarez:

\begin{abstract}
- A instrução que nós tivemos era: vocês podem sonhar... sonhar... sonhar alto... muito alto mesmo. Mandaram que nós sonhássemos bem alto, e, no sonho, nós construíssemos a escola dos nossos sonhos, a escola que sempre desejamos ter. É lógico que eles falaram mil e uma maravilhas do projeto; então, a gente começou a sonhar. Começamos a colocar no papel tudo que queríamos para a nossa escola. (Anita, diretora da Escola Casemiro Alvarez)
\end{abstract}

Este depoimento reflete a expectativa da escola diante da proposta de ação interventora do Estado - que, em tese, seria feita nos moldes dos anseios da escola, respeitando suas particularidades e "estimulando suas vocações".

O incremento da qualidade da educação por meio da implementação de projetos específicos tornou-se um conceito estratégico na formulação da política educacional mineira. Na lógica da SEE-MG, o propósito de construir a "verdadeira escola eficaz" deveria assumir características de objetividade, participação, reforço positivo, acompanhamento, eficácia e eficiência, entre outras. A lógica da inovação e da mudança em busca da melhoria da qualidade apresenta-se de forma marcante nesse discurso, com o propósito de "tutelar" as escolas para que atinjam suas metas de modo mais eficaz, por meio de modificações na estrutura escolar, nos programas, no currículo e na prática educativa. Essa estratégia discursiva reitera uma proposta de projeto que não se efetiva na prática e segue o modelo das propostas neoliberais, gerando políticas educacionais ambíguas e descontextualizadas da realidade das escolas.

Quando se dedica análise mais acurada a propostas como esta, é possível concluir que são programas que desejam salientar uma "escola de fracassos" carente da intervenção do Estado para se reerguer. Ao mesmo tempo, o Estado atribui a maior responsabilidade quanto ao êxito dessa reconstrução da escola à comunidade escolar, por meio da formação de uma "consciência comunitária" criada no "espaço de convivência fraterna". Dessa forma, o Estado passa a imagem de um "benfeitor caridoso", que conta com a participação efetiva da escola na construção de um projeto pedagógico transformador. A realidade que se verifica é bem outra!

\title{
O sonho era de vidro... e se quebrou
}

A fragilidade da proposta de elaboração do PER é observada, com frequência, pela falta de regras claras. As regras e determinações da SEE-MG para a elaboração do PDPI não resolvem problemas reais das escolas pesquisadas e tornam-se confusas, quando são negociadas, de modo ao mesmo tempo técnico, sedutor e competente no âmbito discursivo. 


\section{Valéria Moreira Rezende}

No diagnóstico de suas realidades elaborado pelas escolas, ficaram à mostra fragilidades e problemas a serem solucionados.

- Nós expusemos nossa realidade, colocamos no papel nossas carências e fraquezas, demos nossa cara para bater, e em cima disso construímos um projeto para uma escola como a gente queria... (Neide, supervisora da Escola Casemiro Alvarez)

As duas escolas são distintas, vivem realidades específicas e têm características próprias. $\mathrm{Na}$ Escola Casemiro Alvarez, defende-se a ideia de preparar o aluno para o vestibular. É uma escola de "peso", que afirma oferecer um ensino "diferente das demais escolas da cidade" e se enquadra como "escola de excelência", independentemente do PER que visa resgatar a qualidade da escola pública. Intitula-se "escola-modelo da cidade" e a "preferida no lugar"; o número de alunos matriculados anualmente permanece sempre aquém da procura.

Como mostra o depoimento da auxiliar técnico-administrativa da Escola Casemiro Alvarez, referindo-se ao PER:

- No meu entender, esse projeto não ajudou nada na qualidade da escola. A maioria das coisas que a escolareferência pede a escola já trabalha ao longo desses 40 anos. O que mais deveria trazer não trouxe, que é dinheiro isso sim traduz qualidade. (Cristina - auxiliar técnicoadministrativa da Escola Casemiro Alvarez)

Ou seja, para esta funcionária, a Escola Casemiro Alvarez deve ser reconhecida socialmente como "grife" ou "valor" na comunidade - uma "verdade, criada pela escola, incorporada e percebida como a própria realidade" (DAMASCENO, 2007, p. 165). Uma escola que tem "o corpo docente melhor qualificado entre as escolas públicas", no qual um número considerável de professores também leciona no Ensino Superior...

- Ainda temos muito o que melhorar, a nossa escola luta e se esforça para oferecer o melhor para os nossos alunos. Esse Projeto Escolas-Referência, se for aplicado na íntegra vai ajudar muito a nossa escola, temos alunos muito condição socioeconômica muito baixa. (Laís Cristina, auxiliar técnico-administrativa da Escola Agostino Miranda)

$\mathrm{Na}$ Escola Agostino Miranda, acredita-se que sua função é promover "uma formação geral com ênfase no social", tendo em vista o perfil do seu alunado, desprovido de condições econômicas. Em todo caso, essa escola não anuncia a oferta de um ensino tradicional, afamado e preferido. Ao contrário, há um retrato bem próximo da realidade constatada pelas observações feitas e pelos depoimentos dos atores sociais que atuam nessa escola. 
O Ensino Médio regular em foco: análise do Projeto de Desenvolvimento Pedagógico Institucional (PDPI)

As características expostas pelas duas escolas traduzem perfis diferenciados com objetivos distintos, mas ambas necessitam de recursos e investimentos para a implantação de uma educação de qualidade, de acordo com as proposições do governo mineiro. A forma encontrada para solicitar tais recursos foi a de exacerbar os problemas, isto é, julgou-se necessário "piorar a situação" de cada uma, para chamar a atenção dos respectivos provedores em relação ao atendimento das condições mínimas necessárias para o seu funcionamento. $\mathrm{O}$ depoimento a seguir é elucidativo:

- A situação era e é precária mesmo, mas mesmo assim elas [as escolas] forçaram um pouco a barra. Elas fizeram o diagnóstico, pensando assim: a gente faz um diagnóstico para eles acharem que está ruim mesmo, e que venha tudo que puder vir de bom. (Gisele, técnica da SRE)

Para resolver essa situação, as escolas viram-se obrigadas a elaborar seus PDPIs, pois o repasse de recursos ficou vinculado à existência prévia desse plano. Depois de reiteradas discussões coletivas, apresentaram um conjunto de projetos específicos a serem desenvolvidos, nos quais redesenharam a "escola dos sonhos", idealizado pelo coletivo das comunidades escolares com o propósito de reconstruir a escola pública de excelência.

Contudo, a fragilidade da qual estavam imbuídas as intenções dos propositores do PER fez com que as escolas constatassem que seus sonhos eram de vidro e que logo se quebraram. Na quase totalidade, os projetos específicos elaborados pelas escolas não foram atendidos pela SEE, como mostra o Quadro a seguir, com projetos e ações específicos "barrados" pelo governo mineiro.

Quadro 1

Projetos e ações solicitados pelas escolas e o atendimento da SEE-MG

\begin{tabular}{|l|c|c|}
\hline \multirow{2}{*}{ Projeto/ação } & \multicolumn{2}{c|}{ Atendimento da SEE-MG } \\
\cline { 2 - 3 } & $\begin{array}{c}\text { Escola } \\
\text { Casemiro Alvarez }\end{array}$ & $\begin{array}{c}\text { Escola } \\
\text { Agostino Miranda }\end{array}$ \\
\hline Revitalização do grêmio estudantil & Não atendido & Não atendido \\
\hline Criação de rádio-escola & Não atendido & Não atendido \\
\hline $\begin{array}{l}\text { Criação de associação de pais e } \\
\text { mestres }\end{array}$ & Não solicitado & Não atendido \\
\hline $\begin{array}{l}\text { Criação de jornal informático de } \\
\text { circulação semestral }\end{array}$ & Não solicitado & Não atendido \\
\hline
\end{tabular}




\section{Valéria Moreira Rezende}

Continuação Quadro 1

\begin{tabular}{|l|c|c|}
\hline $\begin{array}{l}\text { Promoção e organização de seminários } \\
\text { com a comunidade }\end{array}$ & Não atendido & Não atendido \\
\hline Capacitação de colegiado escolar & Não solicitado & Não atendido \\
\hline $\begin{array}{l}\text { Implementação de projetos } \\
\text { socioculturais integrados de } \\
\text { reestruturação do planejamento escolar, } \\
\text { para utilização eficaz dos recursos } \\
\text { didáticos }\end{array}$ & Não atendido & Não atendido \\
\hline Criação de central de recurso didático & Não atendido & Não atendido \\
\hline Criação de videoteca & Não atendido & Não atendido \\
\hline Cobertura de quadra de esportes & Concluído & Em construção \\
\hline $\begin{array}{l}\text { Criação de central de recursos } \\
\text { didáticos }\end{array}$ & Não atendido & Não atendido \\
\hline Criação de anfiteatro & Não atendido & Não solicitado \\
\hline $\begin{array}{l}\text { Criação de clube do estudante/centro } \\
\text { de atendimento ao estudante }\end{array}$ & Não atendido & Não atendido \\
\hline $\begin{array}{l}\text { Ampliação/construção de laboratórios } \\
\text { de química, física e biologia }\end{array}$ & Não atendido & Não atendido \\
\hline $\begin{array}{l}\text { Implementação de pesquisas de campo do conhecimento } \\
\text { árearo }\end{array}$ & Não atendido & Não solicitado \\
\hline Reformulação do quadro curricular & Não solicitado & Não atendido \\
\hline $\begin{array}{l}\text { Laboratório de informática } \\
\text { desono }\end{array}$ & Em construção \\
\hline
\end{tabular}

Mais uma vez, evidencia-se a incoerência entre o discurso da SEE$M G$ e o que se realiza na prática. Após criar grande expectativa nas escolas, ficou inviabilizada a efetivação dos projetos sonhados pelas escolas, que necessitam de sustentação financeira dos cofres públicos.

- Então... as coisas ficaram assim... só no sonho, que até agora está longe de tornar realidade. O sonho virou pesadelo. Eu me decepcionei muito com esse projeto. (Analice, professora da Escola Casemiro Alvarez) 
O Ensino Médio regular em foco: análise do Projeto de Desenvolvimento Pedagógico Institucional (PDPI)

- O projeto que nós elaboramos foi totalmente dentro das instruções da SEE, não fizemos nada fora do que eles mandaram. Só que eu digo pra você que o sonho de escola que nós propusemos construir ainda está muito longe de se tornar realidade, e não é por responsabilidade nossa. (Cidinha, professora da Escola Agostino Miranda)

Na previsão do governo do Estado de Minas Gerais, até o final de 2006 , todas as escolas-referência estariam prontas, totalmente equipadas, dentro do que se haviam se proposto a desenvolver, e com seus planos de ação executados ou em execução. Em 2007, uma das técnicas da SRE diz:

- Sobre o projeto que a escola sonhou e dentro dele os projetos específicos que idealizamos, ainda não aconteceram. A SEE criou uma expectativa muito grande e as escolas acreditaram que realmente poderiam elaborar um projeto diferenciado e que teriam retorno, mas isso ainda não aconteceu. Estamos aguardando uma manifestação da SEE quanto à realização desses projetos, as escolas terão que esperar um pouco mais. (Amália, técnica da SRE)

Até o final de 2006, nenhum dos projetos havia sido desenvolvido na totalidade, conforme havia sido proposto. Nota-se uma descontinuidade na política educacional proposta, que não avalia a realidade da escola, não conhece o que a escola está vivenciando na prática, mas impõe a implantação de um projeto que se torna inviável devido a falhas estruturais. Decorridos os três anos do início da implantação do projeto, a escolas ainda careciam de espaço para a realização de suas atividades; por esse motivo, todas as ações que dependiam de espaço físico foram inviabilizadas.

- Foi passado para nós o seguinte: que alguns projetos, aqueles que não precisavam de dinheiro, de verba, as escolas poderiam desenvolver, sim, com seus recursos próprios. Então, ficaram pendentes aqueles que dependiam de verba da SEE, só não sei dizer até quando, não nos passaram nada sobre isso. (Marilda, técnica da SRE)

Houve também o moroso processamento burocrático da Secretaria:

- O processo todo é muito burocrático. Às vezes nem é tanto a questão de não ter recurso; são os trâmites mesmo. O pessoal das escolas fica inconformado: por que o negócio tem que ser tão burocrático assim? Eles queriam que fosse rápido, mais prático, mas tanto eles como a gente somos obrigados a se acostumar com essa morosidade. (Gisele, técnica da SRE) 


\section{Valéria Moreira Rezende}

Assim, aliado à falta de recursos financeiros, há o fato de a Secretaria da Educação dificultar a viabilização das ações do PDPI das escolas, devido ao emperramento que impõe ao andamento da reforma e da adequação dos espaços escolares. Se, por um lado, a comunidade escolar deveria idealizar a "escola dos sonhos", por outro lado, houve um cerceamento desses sonhos, como expressa uma técnica da SRE responsável pelo projeto:

- Eu acho o seguinte: nessa questão do PDPI, eles [0 Estado] perderam um pouco o foco, vamos dizer assim, a noção entre o real e o ideal. O que a gente sabe é que eles colocaram lá, realmente, como proposta mais forte para a elaboração do PDPI, que a escola colocasse todos os seus sonhos e desejos no papel. E a gente sabe que para realizar todos esses sonhos deveria pegar toda a verba proposta para as 223 escolas que estão no PER e investir em 20 ou 30 no máximo. Aí, sim, eles levariam qualidade para a escola. (Ana, técnica da SRE)

Sempre mais, o Estado tem se desobrigado de suas responsabilidades para com as ações sociais, dentre as quais a educação. As instituições escolares têm estado reféns de um modelo centralizador e massificante que, vez ou outra, exibe lampejos de modernização, mudança e inovação, com promessas de proporcionar à escola milagroso futuro. A dinâmica que prevalece na implantação desses modelos prontos de reforma, com vertente neoliberal, é a do apelo ao futuro, priorizando a aquisição de competências, o nível de excelência e o controle de qualidade e reforçando o uso de tecnologias de ponta, em geral desconhecidas pela equipe escolar. Esse modelo idealizado apresenta-se desconectado da realidade da escola, de sua cultura, seus costumes, seus valores, sua história.

Como mostram Zibas, Ferreti e Tartuce (2006), tudo isso vem sendo facilitado pela redução do Estado à função de "negociador" ou "controlador de acordos comerciais". A escola transforma-se segundo o modelo empresarial, ao preço da banalização da vida escolar. Pérez Gómez (2001, p. 136) observa que "[...] poucos duvidam da necessidade de que a escola reconstrua seu próprio papel na sociedade para enfrentar as exigências atuais de um contexto complexo e mutável. O problema é definir até onde e como".

Esse modelo de reformas no campo da educação tomou forma no Brasil devido a uma tradição de conformismo e desigualdades acumuladas:

[...] As reformas só têm conseguido ousar tanto, porque suas "costas quentes" estão apoiadas num tipo de tradição conformista que se nutre de uma racionalidade e política concentradoras, que no Brasil atingiu um entranhamento de tal ordem, forjando esses cinco séculos de injustiça e desigualdades acumuladas. (LINHARES, 2001, p. 156) 
É sabido que as reformas geradas em órgãos administrativos, em âmbito central, encontram nas escolas uma estrutura já pronta e consolidada e provocam nestas uma trama confusa de ações desconexas, filtrando, transformando, escamoteando ou absorvendo, muitas vezes fragmentariamente, as mudanças anunciadas.

A descentralização, se não for acompanhada de uma política que proporcione os recursos humanos e materiais, assim como dos programas de formação de estratégia de coordenação necessárias para evitar a desigualdade e tornar viável a autonomia, não significará mais do que o abandono das instituições ao jogo de interesses alheios aos objetivos educativos. (PÉREZ GÓMEZ, 2001, p. 139)

Tal realidade não é nada mais do que se comprova nas escolas estudadas, no tocante à efetivação de seus planos de ação "sonhados" no PDPI e que, em sua maioria, não se concretizaram. O universo das interpretações ou apropriações feitas em âmbito escolar de tais propostas de implementação de projeto, ou intenções de implantação, constitui campo fértil para se estudar e traçar o perfil da realidade vivenciada pelas escolas, de subserviência em relação ao sistema que as governa e pouco oferece em termos de evidências de sinais de autonomia - o que, por consequência, também interfere na qualidade do ensino.

\section{Considerações finais}

A política de implementação de um projeto que visa a melhoria da qualidade na educação do Ensino Médio em Minas Gerais revela uma sequência de incoerências entre as concepções e ações de intervenção no trabalho escolar. A passividade, o despreparo e a falta de competência constituem representações construídas sobre a escola e seus sujeitos as quais se revelam nos meandros dos programas educacionais do governo. Tais concepções se configuram como estratégias discursivas para legitimar a ação reguladora do Estado sobre o trabalho escolar, gerando políticas educacionais ambíguas e descontextualizadas da realidade das escolas.

Por outro lado, as ações governamentais revelam uma política reguladora, burocrática e normativa que reduziu o PDPI - elaborado no interior da escola como o "projeto dos sonhos" - a um pacote de insumos e serviços pautado em ações de racionalização de gastos seguindo a lógica de eficiência mercadológica. A partir desse escopo de análise, a autonomia da escola é traduzida como desobrigação do Estado em termos de responsabilidade e custos para com a educação.

No que se refere ao cotidiano das escolas de Ensino Médio analisadas nessa investigação, é muito provável que cada professor termine por cons- 
tatar que sua realidade na sala de aula está muito distante dos modelos impostos pelo poder público. Nessa conjuntura, as escolas e seus sujeitos passam a ser reféns de uma política descontextualizada da sua realidade que veicula um discurso falacioso, autoritário e impregnado de retórica vazia, que nada contribui para a alardeada melhoria na qualidade da educação e para a autonomia da escola pública.

\section{Referências}

AZANHA, J. M. P. Educação: temas polêmicos. São Paulo: Martins Fontes, 1995.

BARRETO, E. S. de S. A avaliação na educação básica entre dois modelos. Educação \& Sociedade, Campinas, Centro de Estudos Educação e Sociedade (Cedes), ano XXII, n. 75, 2001. p. 48-66, ago.

BARROSO, J. O estudo da autonomia da escola: da autonomia decretada à autonomia construída. In: BARROSO, J., Ed. O estudo da escola. Porto: Ed. Porto, 1996 p. 167-189.

. Perspectiva crítica sobre a utilização do conceito de qualidade do ensino: consequências para a investigação. In: ESTRELA, A.; FERNANDES, R., COSTA, F. A.; NARCISO, I.; VALÉRIO, O. Eds. Contributos da investigação científica para a qualidade do ensino. Lisboa: Sociedade Portuguesa de Ciências da Educação, 1997. p. 23-43.

CANÁRIO, R. Os estudos sobre a escola: problemas e perspectivas. In: BARROSO, J. Ed. O estudo da escola. Porto: Ed. Porto, 1996. p. 121-149.

DAMASCENO, A. R. Das condições objetivas às representações de boa escola: um estudo da produção e dos produtos das representações dos atores do processo educativo escolar. Tese (Doutorado em Educação) Pontifícia Universidade Católica de São Paulo, 2007.

FRIGOTTO, G.; CIAVATTA, M. Educação Básica no Brasil na década de 1990: subordinação ativa e consentida à lógica do mercado. Educação \& Sociedade. Campinas, Centro de Estudos Educação e Sociedade (Cedes), vol. 24, n. 82, abr. 2003. p. 93-130.

HUTMACHER, W. A escola em todos os seus estados: das políticas de sistema às estratégias de estabelecimento. In: NÓVOA, A., Org. As organizações escolares em análise. Lisboa: Publicações Dom Quixote/Instituto de Inovação Educacional, 1995. p. 43-74.

LIMA, L. Produção e reprodução de regras: normatismo e infidelidade normativa na organização escolar. Inovação, Lisboa, Instituto de Inovação Educacional, vol. 4, n. 1-2, 1991. p. 141-165. 
O Ensino Médio regular em foco: análise do Projeto de Desenvolvimento Pedagógico Institucional (PDPI)

LIMA, L. Construindo um objecto: para uma análise crítica da investigação portuguesa sobre a escola. In: BARROSO, J., ed. O estudo da escola. Porto: Ed. Porto, 1996. p. 15-40.

LINHARES, C. Professores entre reformas escolares e reinvenções educacionais. In: LINHARES, C. (Org). Os professores e a reinvenção da escola: Brasil e Espanha. São Paulo: Ed. Cortez, 2001. p. 137-172.

MARCHESI, A.; MARTÍN, E. Qualidade do ensino em tempos de mudança. Porto Alegre: Artmed, 2003.

NÓVOA, A. Para uma análise das instituições escolares. In: NÓVOA, A. (Org.). As organizações escolares em análise. Lisboa: Publicações Dom Quixote/ Instituto de Inovação Educacional, 1995. p. 13-42.

PÉREZ GÓMEZ, A. I. A cultura escolar na sociedade neoliberal. Porto Alegre: Artes Médicas, 2001.

ZIBAS, D. M. L.; FERRETI, C.; TARTUCE, G. L. B. P. A reforma do Ensino Médio e o protagonismo de alunos e pais. In: VITAR, A.; ZIBAS, D. M. L.; FERRETI, C.; TARTUCE, G. L. B. P. (orgs.). Gestão de inovações no Ensino Médio. Brasília: Liver Livro Editora, 2006. p. 83-138.

\section{Notas}

1 O Projeto Escolas-Referência, proposto pelo governo de Minas Gerais, objetivou oferecer às escolas públicas um suporte que Ihes possibilitasse tornarem-se referência para as outras escolas mineiras. Assim, representariam na rede pública pontos de convergência e de irradiação de boas experiências educacionais. Essas escolas foram escolhidas por sua posição de destaque no sistema escolar, graças à qualidade do trabalho que realizavam, à tradição que possuíam junto à comunidade local ou ao contingente da população que atendiam.

\section{Correspondência}

Valéria Moreira Rezende - Avenida 31, 549. apt. 325, Centro. 38300-104. Ituiutaba, Minas Gerais.

E-mail: valeria@pontal.ufu.br

Recebido em 01 de setembro de 2011

Aprovado em 30 de outubro de 2011 